\title{
COMPARISON OF INTRAVENOUS LIGNOCAINE VS NALBUPHINE IN ATTENUATION OF HEMODYNAMIC RESPONSE TO AWAKE TRACHEAL EXTUBATION IN ENT SURGERIES
}

\author{
Liaquat Ali, Amim Akhter*, Muhammad Saeed ${ }^{* *}$, Usman Khalid ${ }^{* * *}$, Jawad Rehmani**** \\ Fauji Foundation Hospital, Rawalpindi Pakistan, *MDS Hospital, Bagh Azad Jammu \& Kashmir Pakistan, **Combined Military Hospital \\ Peshawar/National University of Medical Sciences (NUMS) Pakistan, ${ }^{* * *}$ Combined Military Hospital Quetta/National University of Medical \\ Sciences (NUMS) Pakistan, ${ }^{* * * *}$ Civil Hospital, Tolti Pakistan
}

\begin{abstract}
Objective: To compare intravenous lignocaine vs. intravenous nalbuphine in terms of mean change in heart rate and mean arterial pressures (MAP) during awake tracheal extubation.

Study Design: Randomized control trial.

Place and Duration of Study: Main Operation Theatre, Combined Military Hospital Rawalpindi, from May 2016 to Dec 2016.

Methodology: After approval of the study by the institution's research ethics committee, the patients meeting inclusion criteria were assigned randomly to one of the two groups by lottery method. On return of spontaneous ventilation, patients in group $\mathrm{L}$ received intravenous lignocaine $1.5 \mathrm{mg} / \mathrm{kg}$ while group $\mathrm{N}$ patients received intravenous Nalbuphine $0.2 \mathrm{mg} / \mathrm{kg}$. Data recorded immediately (T1) and $5 \mathrm{~min}$ after (T2) extubation.

Results: After stratification of data in terms of age, gender, duration of surgery and ASA classification, evaluation of hemodynamic parameters (HR and MAP) between the two groups was done. The mean change in HR in group L was $6.66 \pm 1.53 \mathrm{bpm}$ and in group $\mathrm{N}$ was $4.43 \pm 1.35$. The mean change in MAP in group L was $4.90 \pm 1.49$ $\mathrm{mm}$ of $\mathrm{Hg}$ and in group $\mathrm{N}$ was $3.23 \pm 1.33$. $p$-value in both parameters was found to be less than 0.05 and thus declared significant.

Conclusion: We concluded that intravenous nalbuphine, in the dose of $0.2 \mathrm{mg} / \mathrm{kg}$, is a better attenuator of hemodynamic response to extubation as compared to intravenous lignocaine and provides better stability of Heart rate and Mean arterial Pressure.
\end{abstract}

Keyword: Airway extubation, Hemodynamics, Lignocaine, Mean arterial pressure, Nalbuphine, Pulse.

This is an Open Access article distributed under the terms of the Creative Commons Attribution License (http://creativecommons.org/licenses/by/4.0), which permits unrestricted use, distribution, and reproduction in any medium, provided the original work is properly cited.

\section{INTRODUCTION}

Tracheolaryngeal manipulations during laryngoscopy, intubation and awake extubations lead to a variety of undesirable hemodynamic upsets including wide swings in heart rate and blood pressure. These wide changes can have detrimental effect on susceptible individuals and may precipitate into acute cardiac Failure, Arrhythmias and cerebrovascular injuries. The anesthetist has to face the difficult task of stabilizing hemodynamic parameters while ensuring a smooth extubation as coughing, breath holding and movements can further increase intracranial pressures, intraocular pressures and post-operative hematomas/

Correspondence: Dr Amim Akhter, Main Operation Theatre, Combined Military Hospital, Peshawar Pakistan

Received: 22 Jan 2019; revised received: 11 Aug 2019; accepted: 26 Aug 2019 hemorrhage. In light of above mentioned morbidities, significant energies are focused on reducing sympathetic overdrive during airway manipulations ${ }^{1,2}$.

Various methods and drugs have been tried during airway manipulations to achieve hemodynamic stability and reduce the effects of sympathetic overdrive. These drugs include lignocaine, opioid, Beta blockers and a wide range of other drugs yet a lot of study still needs to be done on finding the best possible agent ${ }^{3-9}$.

Lignocaine is a very useful agent given before extubation to achieve hemodynamic stability especially in awake cases. Studies showed significant decrease in MAP and HR with lignocaine compared to control group ${ }^{10,11}$. Opioids are another class of drugs used for aforementioned 
purpose. In various studies throughout the world fentanyl family has proven to be significant hemodynamic stabilizer ${ }^{12,13}$.

In Pakistan, modern opioids such as remifentanyl and fentanyl family are not easily available. Nalbuphine is readily available in OT and Trauma care setups. Thus, more pragmatic approach demands further research on nalbuphine for its role as attenuator of hemodynamic parameters especially in comparison to the more commonly used Lignocaine. In a study conducted in 2014, Nalbuphine group showed significant hemodynamic stability ${ }^{14}$. When comparing nalbuphine vs. fentanyl in a study published in 2014, results revealed insignificant difference between the two drugs in stabilizing heart rate ${ }^{15}$.

It cannot be stressed more that the results of this study can be significant in terms of Nalbuphine's superior analgesic effects postoperatively as well. The dose of Nalbuphine administered at the time of extubation will not only have beneficial effects of cardiovascular system during emergence from general anaesthesia but will also help in good pain relief in post-operative period especially recovery room. This is an important aspect considering the cost ratio where nalbuphine is normally given in recovery room after lignocaine administration during emergence and extubation; we can utilize a one-time nalbuphine dose preextubation without requiring any lignocaine administration.

No international or local study is available comparing lignocaine and nalbuphine in terms of better attenuator of intubation response, the two most commonly used drugs for blunting the sympathetic drive during airway manipulations. In light of this, the study has been designed to compare the hemodynamic stability of lignocaine vs nalbuphine in awake tracheal extubation. The study should benefit not only the anesthetists in operation theatres but also the patients requiring intubations in wards and emergency trauma centers as nalbuphine is readily available in Pakistan hospital setups. This would in turn benefit the patients as well as the hospital by raising the standards of hospital care systems and preventing avoidable morbidities.

\section{METHODOLOGY}

After the approval of ethical committee of $\mathrm{CMH}$ Rawalpindi, Randomized control study was done from May 2016 to Dec 2016 at Main Operation Theatre Combined Military Hospital Rawalpindi. Sample size was calculated using WHO Calculator. By using mean change in MAP as $3 \pm 2$ for IV Lignocaine group ${ }^{13}$ and $6.01 \pm 4.29$ for Nalbuphine group ${ }^{14}$. Sample size turned out to be 30 in each group. Non-probability consecutive study sampling technique was used.

A total of 60 cases, meeting the inclusion criteria on pre-anesthetic evaluation, were enrolled in the study, to compare the intravenous Lignocaine vs. intravenous Nalbuphine in terms of mean change in heart rate and Mean Arterial Pressures (MAP) during awake tracheal extubation.

Inclusion criteria constituted patients aged 18-60 yrs, ASA 2 or less with surgery time less than 5 hours and undergoing Elective ENT procedures. All patients falling out of above mentioned criteria or undergoing emergency surgery, diffi-cult prolonged intubation timings or multiple intubation attempts or with history of hypertension, Diabetes mellitus, reduced cardiopulmonary reserves, Allergies were excluded. The patients meeting inclusion criteria were assigned randomly to one of the two groups by lottery method.

Pre-medication was done by I.V nalbuphine $0.1 \mathrm{mg} / \mathrm{kg}$, IV metoclopramide $10 \mathrm{mg}$ stat, and induction by I.V propofol $2 \mathrm{mg} / \mathrm{kg}$, I.V Atracurium $0.5 \mathrm{mg} / \mathrm{kg}$. Patients were intubated with cuffed endotracheal tube (size 5-8mm). Following intubation, maintenance of Anaesthesia was achieved by isoflurane MAC $1.5-2 \%$. At the last skin suture, inhalational agent was turned off. End tidal CO2 was kept in slightly higher limits to generate apneic threshold, however, regular breaths were given to ensure end tidal $\mathrm{CO} 2$ remained below $55 \mathrm{~mm} \mathrm{Hg}$. Study drug was administered on return of spontaneous ventilation followed by reversal of neuromuscular blockade 
by neostigmine $0.02 \mathrm{mg} / \mathrm{kg}$ with Glycopyrrolate $0.004 \mathrm{mg} / \mathrm{kg}$. Extubation was performed $3 \mathrm{minu}-$ tes after the administration of study drug.

Group L was administered I.V plain lignocaine $1.5 \mathrm{mg} / \mathrm{kg}$. Group N was administered I.V Nalbuphine $0.2 \mathrm{mg} / \mathrm{kg}$. Heart rate $(\mathrm{HR})$ and mean arterial pressures (MAP) were recorded immediately before extubation (T1) and $5 \mathrm{~min}$ after tracheal extubation (T2). No Beta blocker or antihypertensive drug was given during the whole procedure. Extubation was performed in supine position with all patients in position parallel to the floor. HR was analyzed by standard ECG monitors. MAP was assessed using standardized automated NIBP (Noninvasive Blood Pressure Monitoring).

The results were subjected to statistical analysis using SPSS (Statistical Package for Social Sciences) version 16.0, Chicago, SPSS Inc. Mean \pm SD of heart rate and MAP was calculated at T1 and $\mathrm{T} 2$ and net changes analyzed using t-test between the two groups. Effect modifiers like age, gender, duration of surgery and ASA were controlled by stratification. Post stratification, student t-test was applied and $p$-value less than 0.05 was considered significant.

\section{RESULTS}

Based on the data analyzed, age distribution of the patients was done showing $14(23.3 \%)$ were between ages of 20-29, 21 (35\%) between 30-39 years old, 15 (25\%) were between 40-49 and 10 $(16.7 \%)$ fell in the ages of $50-59$. Mean \pm SD was calculated as $38.8 \pm 10.0$ years for group $\mathrm{L}$ and $35.7 \pm 9.89$ years for group N. Fifty one $(85 \%)$ patients were male while females constituted $9(15 \%)$. Analysis of duration of surgery (min) showed Mean \pm SD of $150.7 \pm 21.9$ min for group $\mathrm{L}$ and $149.99 \pm 17.9 \mathrm{~min}$ for group N. Forty one $(68 \%)$ of total cases were ASA I whereas $19(31 \%)$ were ASA II. The heart rate and MAP values at two timelines for both groups is shown in table-I. The net change in HR and MAP from T1 to T2 was evaluated in both groups in terms of mean \pm SD (table-II).
The data was stratified for age, gender, surgery duration. Stratification for ASA Classification revealed $p$-value of less than 0.05 , for net changes in HR and MAP, in both ASA I and ASA II groups. Age stratification was done based on cohorts between 20 to 29,30 to 39,40 to 49,50 to 59 years and results were found to be significant in all age groups. Stratification in terms of gender

Table-I: Timeline wise Mean \pm SD values of heart rate and map at $t 1$ and $t 2$ in the two groups.

\begin{tabular}{l|c|c}
\hline $\begin{array}{l}\text { Hemodynamic } \\
\text { Parameters }\end{array}$ & $\begin{array}{c}\text { Group L } \\
\text { (Mean } \pm \text { SD) }\end{array}$ & $\begin{array}{c}\text { Group N } \\
\text { (Mean } \pm \text { SD) }\end{array}$ \\
\hline HR at T1 & $83.5 \pm 5.3$ & $74.4 \pm 3.7$ \\
\hline HR at T2 & $90.2 \pm 4.9$ & $78.8 \pm 4.2$ \\
\hline MAP at T1 & $93.9 \pm 5.4$ & $90.8 \pm 3.0$ \\
\hline MAP at T2 & $98.8 \pm 5.3$ & $94.1 \pm 3.2$ \\
\hline
\end{tabular}

Table-II: Mean changes of heart rate and map from $\mathbf{t} 1$ to $\mathbf{t} 2$, between the two groups.

\begin{tabular}{l|c|c|c}
\hline $\begin{array}{l}\text { Hemodynamic } \\
\text { Parameters }\end{array}$ & $\begin{array}{c}\text { Group L } \\
\text { (Mean } \pm \text { SD) }\end{array}$ & $\begin{array}{c}\text { Group N } \\
\text { Mean } \pm \text { SD) }\end{array}$ & $\begin{array}{c}p \text { - } \\
\text { value }\end{array}$ \\
\hline $\begin{array}{l}\text { Heart Rate } \\
\text { (Change) }\end{array}$ & $6.66 \pm 1.53$ & $4.4 \pm 1.35$ & 0.000 \\
\hline MAP(Change) & $4.90 \pm 1.49$ & $3.2 \pm 1.33$ & 0.001 \\
\hline
\end{tabular}

variations revealed significantly low $p$-values in heart rate and MAP changes except in MAP change in females that was found to have $p$-value of 0.756 between lignocaine and nalbuphine groups. Surgery time as effect modifier revealed significant difference in Heart rate changes between both groups. In terms of changes in MAP, results were found to be significant ( $p$-value $<0.05$ ) however $p$-value was found to be 0.327 for surgery time of $160-179 \mathrm{~min}$ and 0.148 for surgery time beyond $180 \mathrm{~min}$.

\section{DISCUSSION}

The main response to Airway manipulations in larynx chiefly comprise of laryngopharyngeal reflexes to noxious stimuli leading to Cough, breath holding, Laryngospasm and the sympathetic/parasympathetic surge of neurotransmitters leading to wide variation in hemodynamic component of body ${ }^{16-19}$.

Pertinent to the benefits of suppressing intubation response is the critical point of differentiation whether one is taking into consideration and criteria, the final outcome (peri-op myocar- 
dial infarction, death) or relative outcomes such as tachycardia, angina, ischemia or arrhythmias.

The vital organs including heart, brain, kidneys all depend upon the mean Arterial pressures to sustain the respective perfusion pressures. This mean arterial pressure in turn is dependent chiefly on cardiac output and systemic vascular resistance. A change is any of these cofactors will negatively effect the fine oxygen demand supply relationship of the organs and therefore can be detrimental in long term care and prognosis.

This is the key reason for establishing that certain vulnerable and compromised patients may not tolerate the hemodynamic and sympathetic outburst effects of airway manipulation unless a quality pharmacological measure is available to keep the parameters in a fine balance. Such vulnerable/compromised patients inarguably include patients with eclampsia, raised intracranial pressures, hypertension crisis or those presenting for cardiac surgeries. These cases have already a compromised balance of oxygen demand supply and minor change in the balance can lead to catastrophic results peri-operatively and post-operatively.

To counter the hemodynamic parameters, anesthetists have tried a lot many drugs and methods. Lignocaine has been used for its hemodynamic stability role. Lignocaine blocks $\mathrm{Na}$ channels and raises the threshold for action potential thus modifying sympathetic outflow ${ }^{20}$. In numerous other studies, opioid family has shown significant results. In Pakistan where fentanyl family drugs are not easily available, nalbuphine is useful alternative in operation theatres and trauma care settings.

The results of our study clearly demonstrate superior abilities of intravenous nalbuphine in attenuating hemodynamic responses to airway manipulations during extubation, in comparison to lignocaine. The $p$-value of less than 0.05, in both Heart rate changes and Mean Arterial Pressure changes, was found and thus declared significant. This can be co-related indirectly with many local and international researches. Lignocaine and opioids are both proven attenuators of hemodynamic responses.

In a study conducted in 2011 by Deok Hee Lee, lignocaine proved to be significant attenuator of both MAP and HR during airway manipulation compared to control group, $p$-value of less than 0.05 was seen ${ }^{10}$. The use of Lignocaine as attenuator of hemodynamic responses has been used for many decades. In a study done by Arun Bidwai in 1979, he proved significant attenuation effects of intravenous lignocaine on extubation ${ }^{11}$.

Remifentanyl has been studied for its hemodynamic stability effects extensively ${ }^{12}$. In 2011, Lee et al compared the attenuation effects of $1.5 \mathrm{mg} / \mathrm{kg}$ I.V lignocaine with Remifentanyl, an opioid of fentanyl family. It was found that Remifentanyl was a far better attenuator of both HR and MAP during extubation period than lignocaine ${ }^{13}$. Thus opioids are as effective attenuators of intubation responses, if not better than lignocaine.

In 2014, Mohammad Tariq observed the attenuation effects of $0.2 \mathrm{mg} / \mathrm{kg}$ nalbuphine and found significant $(p<0.05)$ attenuation of $\mathrm{HR}$ and MAP during airway manipulation ${ }^{14}$. In the same year, Sharma et al compared nalbuphine vs fentanyl for attenuation of intubation responses and found both drugs comparable in terms of heart rate ${ }^{15}$.

Finally, results of major studies throughout the world have shown lignocaine and nalbuphine as significant attenuators of intubation response. No study was hitherto done on comparing these two drugs with one another. This study was strongly required in Pakistan where fentanyl family is only available in major centers and majority of hospitals have easy access to Nalbuphine as an opioid of choice. Thus it can be established with confidence that Nalbuphine can be used as a far superior attenuator of hemodynamic responses during extubation than lignocaine, as has been shown by our study as well.

We are of the view that nalbuphine use should be encouraged for attenuating hemody- 
namic responses to awake extubation, compared to traditional lignocaine use. It has both hemodynamic stability effect and its added analgesic effects have more beneficial results for the patients post operatively. Anyhow limitation of our study is that it is a single center study and the sample size is not enough to generalize it to the whole population. Therefore, large multi centers study should be carried out before strongly recommending this drug for routine awake extubation.

\section{CONCLUSION}

We concluded that intravenous nalbuphine, in the dose of $0.2 \mathrm{mg} / \mathrm{kg}$, is a better attenuator of hemodynamic response to extubation as compared to intravenous lignocaine and provides better stability of Heart rate and Mean arterial Pressure.

\section{CONFLICT OF INTEREST}

The study has no conflict of interest to declare by any author.

\section{REFERENCES}

1. Artime CA, Hagberg CA. Tracheal extubation. Respir Care 2014; 59(6): 991-02.

2. Kishnani P, Tripathi D, Trivedi L. Hemodynamic stress response during insertion of proseal laryngeal mask airway and endotracheal tube-a prospective randomized comparative study. Int J Res Med 2016; 5(2): 34-38.

3. Chen YQ, Jin XJ, Liu ZF, Zhu MF. Effects of stellate ganglion block on cardiovascular reaction and heart rate variability in elderly patients during anesthesia induction and endotracheal intubation. J Clin Anesth 2015; 27(2): 140-45.

4. Khalawe N, Abbass HF, Ali AS. Comparative study between lidocaine and Metoprolol on hemodynamic attenuation during laryngoscope and endotracheal intubation. Global Sci J 2018; 6(10): 330-44.

5. Kothari D, Tandon N, Singh M, Kumar A. Attenuation of circulatory and airway responses to endotracheal extubation in craniotomies for intracerebral space occupying lesions: Dexmedetomidine versus lignocaine. Anesth Essays Res 2014; 8(1): 78-82.

6. Majumdar S, Das A, Das H, Bandyopadhyay S, Hajra BK, Mukherjee D. Comparative evaluation of oral gabapentin versus clonidine as premedication on preoperative sedation and laryngoscopic stress response attenuation for the patients undergoing general anesthesia. Perspect Clin Res 2015; 6(4): 211-16.

7. Kotwani MB, Kotwani DM, Laheri V. A comparative study of two doses of magnesium sulphate in attenuating haemodynamic responses to laryngoscopy and intubation. Int J Res Med Sci 2016; 4(7): 2548-55.

8. Nagrale MH, Indurkar PS, Pardhi CS. Comparative study on haemodynamic response to extubation: Attenuation with lignocaine, esmolol, propofol. Int J Res Med Sci 2016; 4(1): 144-51.

9. Mahajan L, Kaur M, Gupta R, Aujla KS, Singh A, Kaur A. Attenuation of the pressor responses to laryngoscopy and endotracheal intubation with intravenous dexmedetomidine versus magnesium sulphate under bispectral index-controlled anaesthesia: A placebo-controlled prospective randomised trial. Ind J Anaesth 2018; 62(5): 337-43.

10. Lee D, Park S. Effects of $10 \%$ lidocainespray on arterial pressure increase due to suspension laryngoscopy and cough during extubation. Korean J Anesthesiol 2011; 60: 422-27.

11. Bidwai AV, Bidwai VA, Rogers CR. Blood-pressure and pulserate responses to endotracheal extubation with and without prior injection of lidocaine. Anesthesiology 1979; 51(2): 171-73.

12. Kutlesic MS, Kutlesic RM, Mostic-Ilic T. Attenuation of cardiovascular stress response to endotracheal intubation by the use of remifentanil in patients undergoing Cesarean delivery. J Anesth 2016; 30(2): 274-83.

13. Lee H, Koo B, Jeong J. Differential effects of lidocaine and remifentanil on response to the tracheal tube during emergence from general anaesthesia. Brit J Anaesth 2011; 106(3): 410-15.

14. Tariq AM, Iqbal Z, Qadirullah. Efficacy of nalbuphine inn preventing haemodynamic response to laryngoscopy and intubation. J Postgrad Med Inst 2014; 28(2): 211-16.

15. Sharma N, Parikh H. A Comparative study of hemodynamic responses to intubation:fentanyl versus nalbuphine. GMJ 2014; 2(1): 48-53.

16. Russell WJ, Morris RG, Frewin DB, Drew SE. Changes in plasma catecholamine concentration during endotracheal intubation. $\mathrm{Br}$ J Anaesth 1981; 53(8): 837-39.

17. Kayhan Z, Aldemir D, Mutlu H. Which is responsible for the haemodynamic response due to laryngoscopy and endotracheal intubation? Catecholamines, vasopressin or angiotensin? Eur J Anaesth 2005; 22(10): 780-85.

18. Perkins ZB, Gunning M, Crilly J, Lockey D, O'Brien B. The haemodynamic response to pre-hospital RSI in injured patients. Injury, Elsevier Ltd 2013; 44(5): 618-23.

19. Gupta A, Wakhloo R, Gupta V, Mehta A, Kapoor BB. Comparison of esmolol and lignocaine for atttenuation of cardiovas-cular stress response to laryngoscopy and endotracheal intubation. JK Sci J Med Educ Res 2009; 11(1): 78-81.

20. Morgan GE, Mikhail MS, Butterworth JF, Mackey DC, Wasnick JD. Clinical Anesthesiology $5^{\text {th }}$ ed, USA: Mc Graw Hill 2013; 16(1): 265-75. 